I.A. Carrascal ${ }^{1}$, C. Fernández-Diego ${ }^{2 *}$, J.A. Casado ${ }^{1}$, S. Diego ${ }^{1}$, I. Fernández ${ }^{2}$, A. Ortiz $^{2}$

\title{
QUANTIFICATION OF KRAFT PAPER AGEING IN MINERAL OIL IMPREGNATED INSULATION SYSTEMS THROUGH MECHANICAL CHARACTERIZATION
}

\author{
${ }^{1}$ LADICIM (Laboratory of Materials Science and Engineering), School of Civil \\ Engineering, University of Cantabria, Avenida Los Castros 44, 39005 Santander, \\ Cantabria, Spain. \\ ${ }^{2}$ Electrical and Energy Engineering Department, School of Industrial and \\ Telecomunications Engineering, University of Cantabria, Avenida Los Castros, \\ 39005 Santander, Cantabria, Spain.
}

*Corresponding author: cristina.fdezdiego@unican.es

Phone: 0034942201380

\section{ABSTRACT}

Most power transformers use Kraft paper as the main solid insulation between the winding conductors. Dielectric oil used in transformers as an insulating and cooling fluid typically has an operating temperature range of $60-90^{\circ} \mathrm{C}$. These service temperatures can cause slow degradation of both the oil and the insulating paper winding, with a loss of mechanical and dielectric properties. In this sense, this paper proposes the possibility of analysing paper degradation through the loss of its mechanical properties. An accelerated thermal ageing of the paper in mineral oil was carried out at temperatures of 110,130 and $150^{\circ} \mathrm{C}$ over different periods of time, in order to obtain information on the kinetics of the ageing degradation of the paper. The evolution of the mechanical properties and micro mechanisms of paper failure are analysed as a function of temperature and ageing time. Finally, the results obtained are compared with the traditional method of degradation analysis, based on the degree of polymerisation (DP) measurement.

KEYWORDS: Kraft paper, power transformer, thermal ageing, degradation, tensile test, degree of polymerisation 


\section{ACKNOWLEDGMENTS}

The authors are grateful for the funding received to carry out this work from the State Scientific and Technical Research and Innovation Plan under the DPI2013-43897-P grant agreement, financed by the Government of Spain. 


\section{INTRODUCTION}

Electric power systems are of great importance in the daily life of modern societies and their reliability during operation depends on the lifespan of their components (Zhuravleva et al. 2016). Power transformers are one of these critical elements since they carry out essential functions in the generation and transmission of power (Perrier et al. 2016). Most of the transformers used in electric power systems are currently oil immersed transformers that also contain a solid insulation. The oil used in this type of transformers not only provides a cooling function, but also an electric insulating function together with the dielectric solid materials. This type of transformers can contain up to 12 tonnes of paper insulation wrapped around the windings and 40 tonnes of insulating oil. Their operation temperature is usually between $60-90^{\circ} \mathrm{C}$ and can have a lifespan of up to 40 years.

The most widely used dielectric liquid in power transformers is mineral oil, obtained from crude oil which has shown suitable thermal and dielectric properties to perform their cooling and insulation functions respectively (Fofana 2013). At the same time, Kraft paper (90\% cellulose, 6-7\% lignin and 3-4\% pentosans) (Emsley and Stevens 1994) is by far the most widely used solid material due to economic factors and ease of manufacture, although other materials are being used to insulate the areas where the operating temperature is believed to be high (Ding and Wang 2008).

Cellulose insulating materials have desirable physical and chemical properties for use as electrical insulators, although they degrade over time. Therefore, the degradation of cellulose materials is a critical factor that determines the life expectancy of a transformer (Prevost et al. 2006). During transformer operation, the dielectric solid undergoes a slow decomposition with loss of its mechanical strength due to the effects of temperature, electrical and mechanical stresses, and the chemical reactions that occur over time. It is commonly established that the main factor influencing the degradation of paper insulation is the temperature (Oommen and Prevost 2006; Prevost et al. 2006). During the operation of the transformer, not only does the dielectric paper undergo continuous degradation, but also the oil progressively loses its dielectric and thermal properties, affecting the insulating and cooling systems of the machines. For this reason, it is essential 
to characterise the degradation of the paper and the oil. However, although the state of the oil in a power transformer can be evaluated directly because sampletaking is easily accessible, the sampling of a piece of paper from the windings of transformers in service is not possible.

Thus, non-destructive techniques are used to determine the paper's state. These techniques are based on the measurement of by-products derived from the deterioration of cellulose (furanic compounds, water, $\mathrm{CO}_{2}, \mathrm{CO}$, etc.) which can be used to indirectly evaluate the condition of the insulation paper, once they have dissolved in the oil. Nevertheless, these techniques, which are indirect methods to determine cellulose degradation, have the disadvantage that they depend on the knowledge of the history of the transformer and its components (Emsley and Stevens 1994; Hill et al. 1995; Levchik et al. 1997; Heywood et al. 2000; Kalariya et al. 2007).

Since the lifetime of a transformer depends fundamentally on the state of the solid insulation, as has been shown by different studies (Emsley and Stevens 1994; Heywood et al. 2000; Carcedo et al. 2016), a detailed understanding of the mechanisms of cellulose degradation is needed to predict the remaining life of the insulating paper and give an early warning of premature failure, (Hill et al. 1995). One way to define the kinetic models of solid insulation degradation is through the post-mortem analysis of power transformers, since this type of study attempts to relate the results obtained by the indirect methods of diagnosis described above with the actual state of the components of the machine (Knoch et al. 2007; Prevost et al. 2007; Martins et al. 2011; Leibfried et al. 2011).

However, these life predictions from actual data collected from the transformers in service are complex because there is a large number of operational variables involved during transformer performance and additionally, they are extremely disperse (Madavan and Balaraman 2016). In view of this, laboratory tests are used to provide a strict control of the experimental variables.

Furthermore, these laboratory experiments, performed at constant temperature, need several months to produce results because they are carried out at higher temperatures than service ones. These laboratory tests are used to provide an overview of the chemical process associated with the ageing of the paper (Hill et al. 1995 part1; Hill et al. 1995 part2; Hill et al. 1996; Levchik et al. 1997; Gasser 
et al. 1999; Murugan and Ramasamy 2015; Carcedo et al. 2016) and they considerably reduce the economic costs.

The method most commonly used in the literature for characterising the degradation of the dielectric paper involves the determination of the degree of polymerisation (DP) through the measurement of the viscosity. The bond breaking of the major cellulose chains caused by the deterioration results in a decrease in the average molecular weight of the chains. This fact not only causes variations in the physical properties of the oil (generating a significant amount of water, furans, $\mathrm{CO}$ and $\left.\mathrm{CO}_{2}\right)$ (Hill et al. 1995 part1; Hill et al. 1995 part2; Hill et al. 1996; Levchik et al. 1997; Gasser et al. 1999), but also it has been shown that paper undergoes a decrease in its mechanical properties (Lundgaard et al. 2007). For this reason, several studies have proposed models that establish the relationship between the variation of the tensile strength and the degree of polymerisation (DP) over time (Hill et al. 1995 part2, Hill et al. 1996, Gasser et al. 1999). Other more recent studies (Mirazie et al. 2009; Hoom et al. 2010; Abelmalik et al. 2013; Rodriguez-Celis et al. 2015; Widyanugraha et al. 2015) have performed the comparison between the variation of the tensile strength and different parameters associated with the properties of the oil. For example, one of these parameters is the content of gases dissolved in the oil as: $\mathrm{CO}, \mathrm{CO}_{2}, \mathrm{H}_{2}, \mathrm{CH}_{4}, \mathrm{C}_{2} \mathrm{H}_{4}, \mathrm{C}_{2} \mathrm{H}_{6}$ and $\mathrm{C}_{2} \mathrm{H}_{2}$. Studies like the one carried out by Hoom (Hoom et al. 2010] have obtained mathematical models that relate the tensile strength with the content of $\mathrm{CO}$ and furans dissolved in the oil as a function of the ageing temperature.

Other studies (Mirazie et al. 2009; Abelmalik et al. 2013) have related the evolution of the breakdown voltage in oil and paper, acidity and water content in the oil with the rupture stress, making a comparison between the results obtained from both parameters over time and at different ageing temperatures. There are also works such as the one carried out by Ding (Ding and Wang 2008) in which mathematical models have been proposed for the calculation of the degradation experienced by the insulation paper as a function of time and temperature through the measurement of the DP and tensile index.

However, in all these studies, only strength or tensile index have been analysed, not taking into account the evolution of other important mechanical properties such as strain or energy consumed per unit volume, which are closely related to the brittleness of the material. 
Considering the significance that other mechanical parameters might have in the analysis of paper degradation, this paper attempts to correlate the variations suffered by different mechanical properties (strength, Young's Modulus, yield stress, energy consumed, etc.) with the degree of degradation of Kraft paper. The final aim is to establish whether data obtained from the stress-strain curve might be able to provide a new method which can predict dielectric paper failure.

Additionally, a mathematical model has been defined based on the degree of polymerisation to predict the remaining life of Kraft paper. The information provided by this method has been compared with that based on the stress-strain curve. This will be used to observe which of the two methods supplies the more useful information and whether the end-of-life criteria of the dielectric material established until now are the most suitable for guaranteeing the reliability of the solid insulation.

\section{MATERIAL}

This work has studied the behaviour of Kraft paper, whose properties are gathered in Table 1. Kraft paper was cut into strips of $250 \mathrm{~mm}$ in length and $15 \mathrm{~mm}$ wide. Due to paper anisotropy, these strips were cut with different fibre direction angles (longitudinal, transverse and $45^{\circ}$ ). This work aims to assess the degradation rate of Kraft paper immersed in mineral oil (Table 2) taking into account paper anisotropy through mechanical analysis.

Table 1. Kraft paper properties.

\begin{tabular}{|l|l|l|}
\hline Property & Units & Value \\
\hline Grammage & $\mathrm{g} / \mathrm{m}^{2}$ & 149.3 \\
\hline Thickness / 5 sheets & $\mu \mathrm{m}$ & 198 \\
\hline Apparent density & $\mathrm{kg} / \mathrm{m}^{3}$ & 754 \\
\hline Moisture & $\%$ & 6.3 \\
\hline Tensile Index & $\mathrm{Nm} / \mathrm{g}$ & 108.4 \\
\hline Ash & $\%$ & $<0.6$ \\
\hline Aqueous extract & $\mathrm{ms} / \mathrm{m}$ & 1.5 \\
\hline conductivity & & \\
\hline
\end{tabular}




\begin{tabular}{|l|l|l|}
\hline $\begin{array}{l}\text { Dry breakdown strength in } \\
\text { air }\end{array}$ & $\mathrm{kV} / \mathrm{mm}$ & 8.9 \\
\hline
\end{tabular}

Table 2. Mineral oil properties.

\begin{tabular}{|l|l|l|}
\hline Property & Units & Value \\
\hline Viscosity, $40 \circ \mathrm{C}$ & $\mathrm{mm}^{2} / \mathrm{s}$ & 7.6 \\
\hline Viscosity, $-30 \circ \mathrm{C}$ & $\mathrm{mm}^{2} / \mathrm{s}$ & 730 \\
\hline Pour point & oC & -63 \\
\hline Flash point & oC & 154 \\
\hline Water content & $\mathrm{mg} / \mathrm{kg}$ & $<20$ \\
\hline Breakdown voltage & $\mathrm{kV}$ & $40-60$ \\
\hline Acidity & $\mathrm{mg} \mathrm{KOH} / \mathrm{g}$ & $<0.01$ \\
\hline Density, $20 \circ \mathrm{C}$ & $\mathrm{kg} / \mathrm{dm}^{3}$ & 0.877 \\
\hline
\end{tabular}

\section{EXPERIMENTAL METHODOLOGY}

\section{Thermal ageing}

Kraft specimens were placed into a stainless steel vessel which has a volume of 1 litre and two connections, one for the vacuum pump and another for the vacuometer, as shown in Fig. 1.

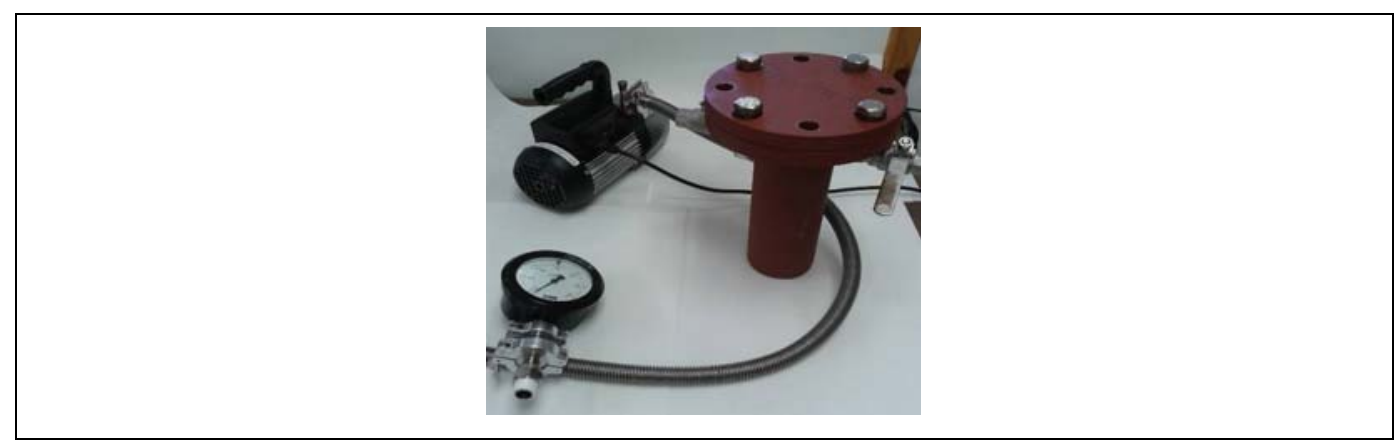

Fig. 1: Vessel for thermal ageing

Once the vessel was closed, it was connected to a vacuum pump until reaching approximately 1 mbar. It was then placed in an oven at $100^{\circ} \mathrm{C}$ for 24 hours, providing samples with a moisture content of $12 \%$. 
After that, $750 \mathrm{ml}$ of mineral oil were introduced into the vessel with a nitrogen headspace of $25 \%$ by volume. The thermal ageing was then carried out at different temperatures: 110,130 and $150^{\circ} \mathrm{C}$, and different samples of paper were taken periodically to analyse their properties.

\section{Traditional characterisation of cellulose degradation}

The method most commonly used for characterising cellulose degradation involves the determination of the chain scission number as a function of the degree of polymerisation (DP). The degree of polymerisation was determined according to ASTM D4243 by measuring the kinematic viscosity of the paper in solution (the viscosity is related to the molecular weight by the Mark-Houwink Sakurada equation). The viscosity-average DP was obtained based on measurements at $20^{\circ} \mathrm{C}$ using an automatic viscometer equipped with a two-sphere Ubbelohde tube. Each paper strip was first de-oiled using distilled hexane. Subsequently, the paper was dissolved in a solution of deionised water and bis(ethylenediamine) copper (II) hydroxide which is the viscosimetric solvent. After dissolution of the paper in the prepared solution, its specific viscosity was determined. From this result the intrinsic viscosity of the solution was deduced, and from this data the DP was obtained. For this, it is necessary to know the moisture of the sample, which was determined using Karl Fischer titration.

\section{Tensile characterisation of Kraft paper}

For tensile testing, a universal servo hydraulic test machine was used with an axial load cell of $\pm 1 \mathrm{kN}$ capacity, an actuator of $\pm 50 \mathrm{~mm}$ of dynamic stroke and equipped with pneumatic flat grips. The ends of the paper strips were protected with adhesive paper to prevent the grips from causing any damage to the paper. The length of the paper strips for the measurement of the strain was set at $180 \mathrm{~mm}$ and the rate of separation of the grips was set at $20 \mathrm{~mm} / \mathrm{min}$ until the specimen rupture, according to ISO 1924-2 2009. The parameters obtained in the test were 
Young's Modulus, E, yield stress, $\sigma \mathrm{y}$, rupture strength, $\sigma \mathrm{R}$, strain under ultimate strength, $\varepsilon \mathrm{cm}$, and energy consumed per unit volume of the failure zone, ER.

\section{Fractographic analysis}

Finally, the fractured surfaces of the tensile tested paper samples were analysed by a scanning electron microscope (SEM), brand Carl Zeiss, model EVO MA15, to identify the failure mode after different stages of thermal ageing.

\section{ANALYSIS AND RESULTS}

Any attempt to characterise Kraft degradation should satisfy two requirements. Firstly, it has to include the essential physical aspects of the degradation process. Secondly, its mathematical expression must be in agreement with the experimental data. This work has started with the development of a cellulose degradation equation, expressed in terms of DP, and has followed with the study of mechanical characterisation. This could be an alternative method which offers a more detailed analysis of dielectric paper degradation.

\section{Paper ageing model}

Figure 2 shows the evolution of the degree of polymerisation, DP, as a function of the ageing time and the temperature at which thermal ageing took place. It can be seen that the DP decreases over time and this decrease becomes faster when the ageing temperature increases. 


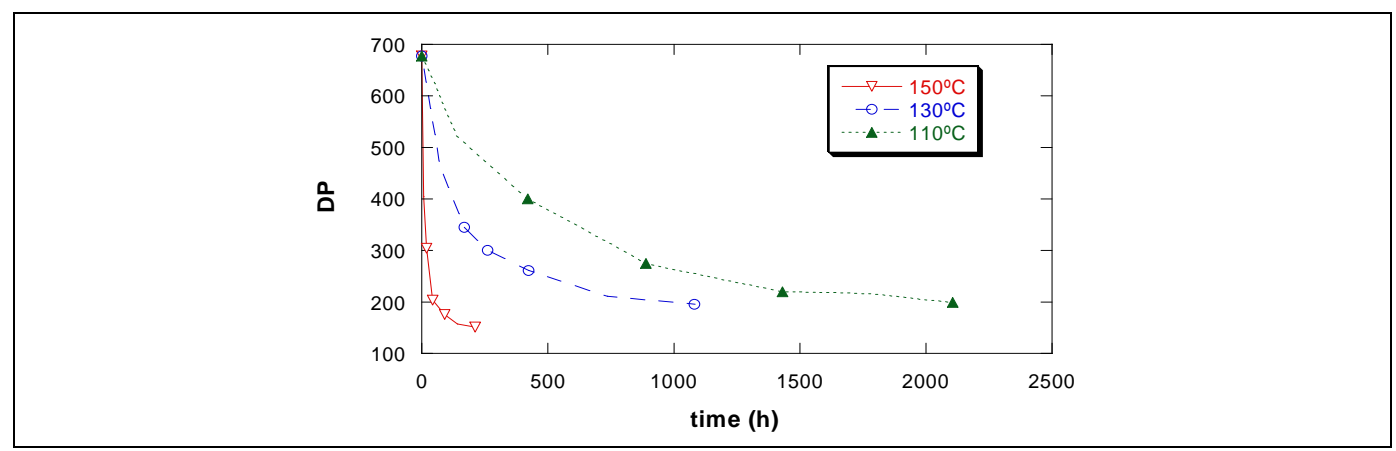

Fig. 2: Evolution of the DP as a function of time and temperature

In order to define a paper deterioration model based on $\mathrm{DP}=\mathrm{f}(\mathrm{t}, \mathrm{T})$, the damage parameter D is defined based on Eq. 1,

$$
D=1-\frac{D P_{i}}{D P_{0}}
$$

The damage can be obtained from the DPi value in any situation of time $(t)$ and temperature (T) and from the DP0, which is the value of the DP of the original paper not subject to ageing $(\mathrm{DP} 0=678)$. In this way, the paper without ageing will present no damage, $\mathrm{D}=0$. Figure 3 shows the evolution of the damage parameter, $\mathrm{D}$, with $\mathrm{t}$ for different ageing conditions. This figure shows the good correlation between the experimental data and the adjustment performed according to Eq. 2.

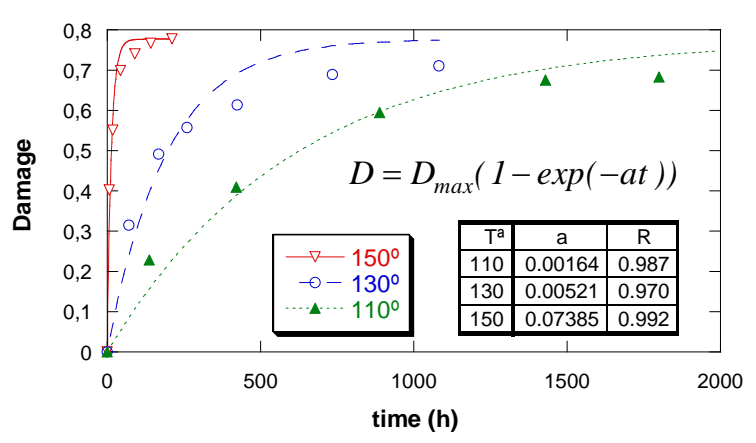

Fig. 3: Evolution of the damage, $\mathrm{D}$, in function of the $\mathrm{t}$ and the $\mathrm{T}$

$$
D=D_{\max }(1-\exp (-a t))
$$


where the constant a depends on the ageing temperature and Dmax is the maximum value reached experimentally by the damage, $\operatorname{Dmax}=0.777$. The constant a can be expressed by means of an exponential law Eq. 3 as a function of the ageing temperature.

$$
a=3,626 \cdot 10^{-8} \cdot \exp (0.0952 \cdot T)
$$

Finally, the degree of polymerisation can be expressed by means of Eq. 4 as a function of the time and the temperature.

$$
D P_{i}=D P_{0}\left(1-D_{\max }(1-\exp (-a t))\right)
$$

Figure 4 compares the experimental values with those obtained by the behaviour model for the temperatures under study, as well as the theoretical behaviour for other temperatures, including those typical of the operation of power transformers.

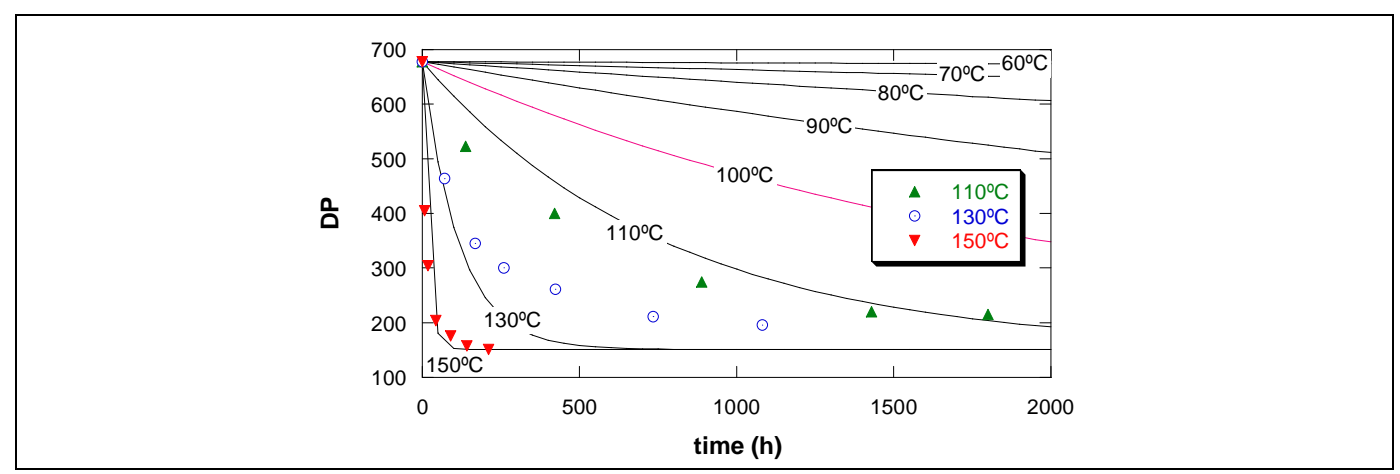

Fig. 4: Comparison of the DP behaviour model and experimental values

A critical degree of polymerisation DPc $=200$ is often used as the end-of-life criterion (Lundgaard et al. 2007). Using Eq. 5, if the DPc is entered as Di, the estimated life time is obtained as a function of the operating temperature of the transformer, Fig. 5. It can be verified that for a temperature of $60^{\circ} \mathrm{C}$, under normal conditions of operation, the estimated life time is about 25 years and as the ageing rate increases, the time decreases logarithmically.

$$
t_{i}=-\frac{1}{a} \cdot \ln \left(1-\frac{D}{D_{\max }}\right)
$$




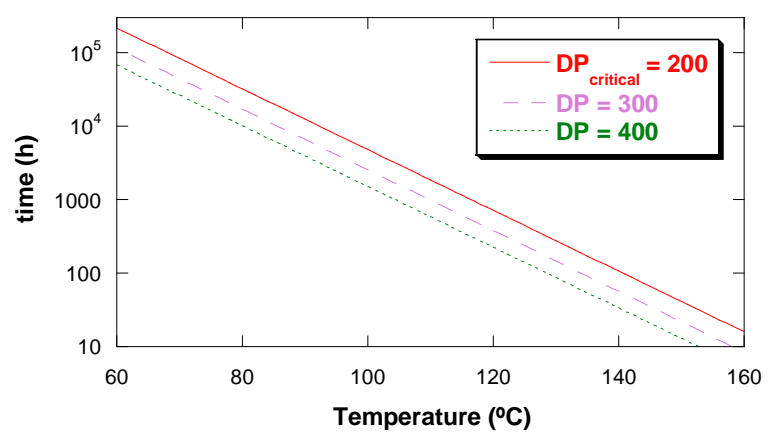

Fig. 5: Estimated time of life as a function of the temperature

\section{Alternative method to evaluate the degradation degree of the paper}

When the mechanical behaviour of the original paper is analysed as a function of the fibre direction angle, gathered in Fig. 6, a strong anisotropy can be verified. It can be observed that the rupture strength, when the paper fibres are in the same direction as that with which the test machine applies the load, is two times the strength obtained when the fibres are in cross direction to the test machine, while the strain is half. The strength values when the fibres are at $45^{\circ}$ are intermediate and are discarded for the rest of the study.

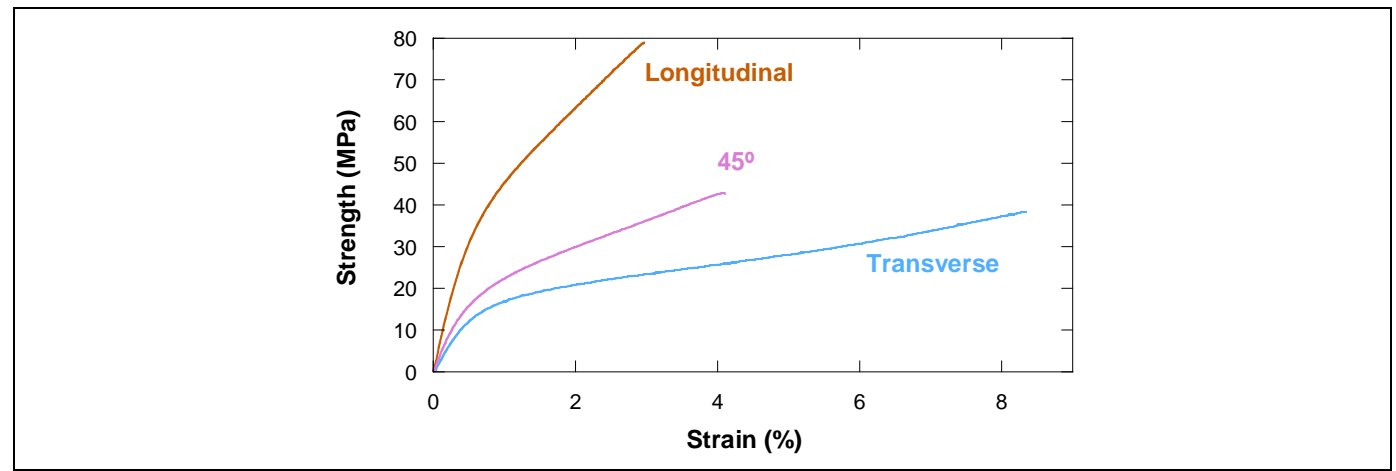

Fig. 6: Anisotropy of Kraft paper

Figure 7 shows the evolution of the strength-strain curves obtained for different ageing times and an ageing temperature of $150^{\circ} \mathrm{C}$. 


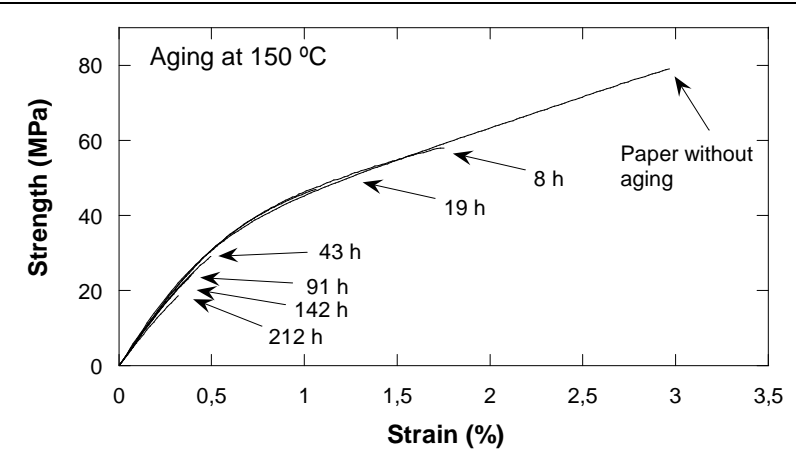

Fig. 7: Influence of the t of ageing on strength

It can be verified in Fig. 7 that the curves are practically coincident and the rupture points have to be indicated on the graph to distinguish them. In view of the results, it can be observed that the Young's Modulus can hardly provide any information on the degree of degradation, since it is practically the same in all the curves and only in those states of severe degradation does it show a slight decrease. As for the yield stress, $\sigma y$, in more than half of the analysed samples its value is the same as that of the rupture strength, due to the fragility of the most deteriorated samples. It will be the parameters of rupture strength and strain under ultimate strength that clearly depend on the paper degradation.

Figure 8 shows the evolution of these two parameters with the time of ageing for the three ageing temperatures analysed. The rupture strength and strain under ultimate strength are considerably affected by time and temperature. Regarding the energy consumed in the rupture, ER, which is a combination of strength and strain, time and temperature have a greater effect, as can be seen in Fig. 9. It can be observed in Figs. 8 and 9 that there is an important linear decrease in the properties at the beginning of thermal ageing and a later stabilisation of the values of the analysed properties, but with relatively poor values. In addition, the loss of properties is observed in a similar way when fibre orientation is longitudinal and transverse. 


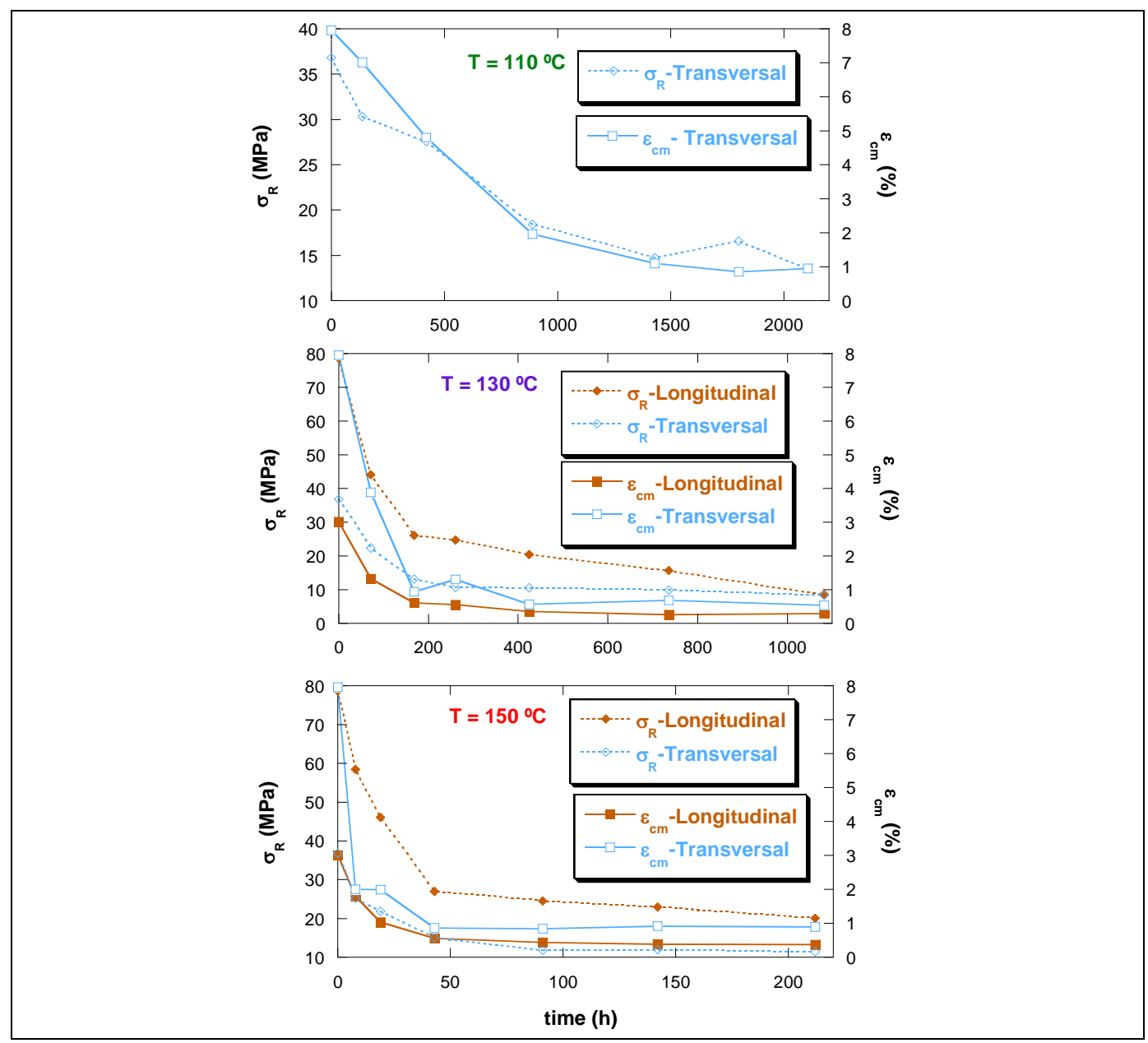

Fig. 8: $\sigma_{\mathrm{R}}$ and $\varepsilon_{\mathrm{cm}}$ as a function of the ageing $\mathrm{t}$

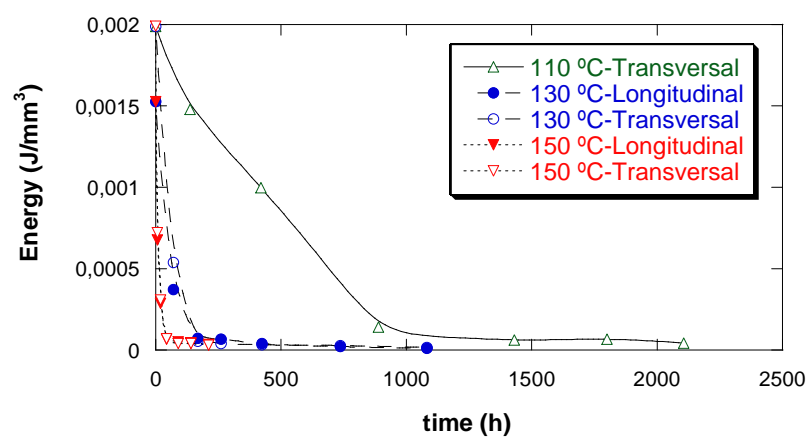

Fig. 9: $E_{R}$ as a function of ageing time and temperature

It is verified from the two figures above that the critical ageing times, tc, for which the maximum loss of mechanical properties is produced, are 30,175 and 1000 hours for the ageing temperatures of 150,130 and $110^{\circ} \mathrm{C}$, respectively. These critical times represent the period required to obtain DPC $=200$. It can be observed in Fig. 10 that before reaching the DPC, a DP of around 300, the mechanical properties are already minimal. Therefore, it might be of interest to 
redefine the critical values of DP (200) and strength (50\% of initial value), as it is possible that the general failure mode of the Kraft changes before obtaining these values of DP and $\sigma R$.

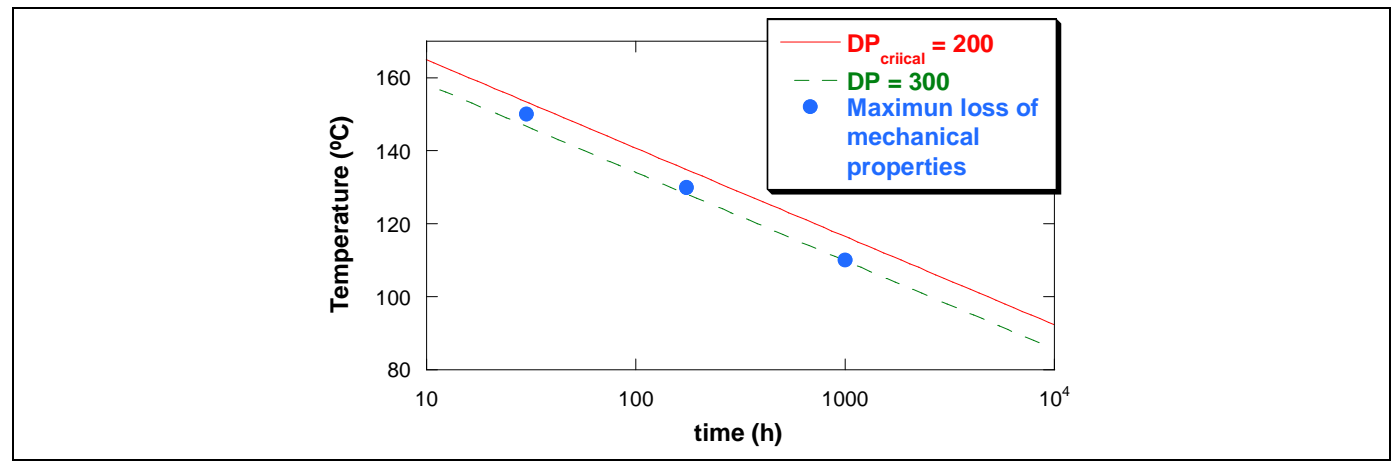

Fig. 10: Comparison between tc and DPc

Figure 11 gathers the correlation between the degree of polymerisation and the three variables obtained in the tensile tests, $\sigma \mathrm{R}, \varepsilon \mathrm{cm}$ and ER. It is possible to verify the existence of a linear relationship between these parameters and DP up to the value close to 300 . After this degree of degradation, the mechanical properties hardly change.

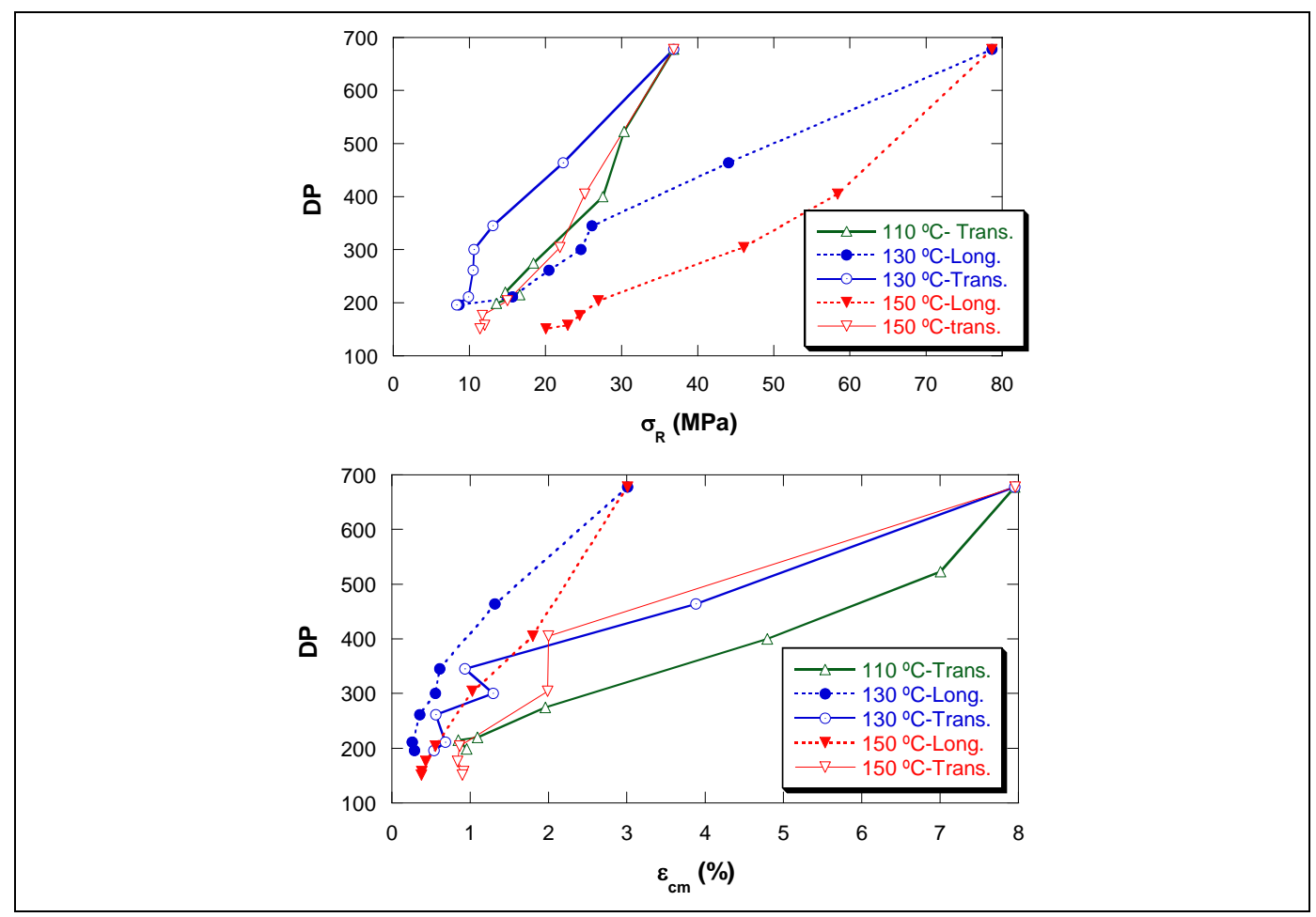




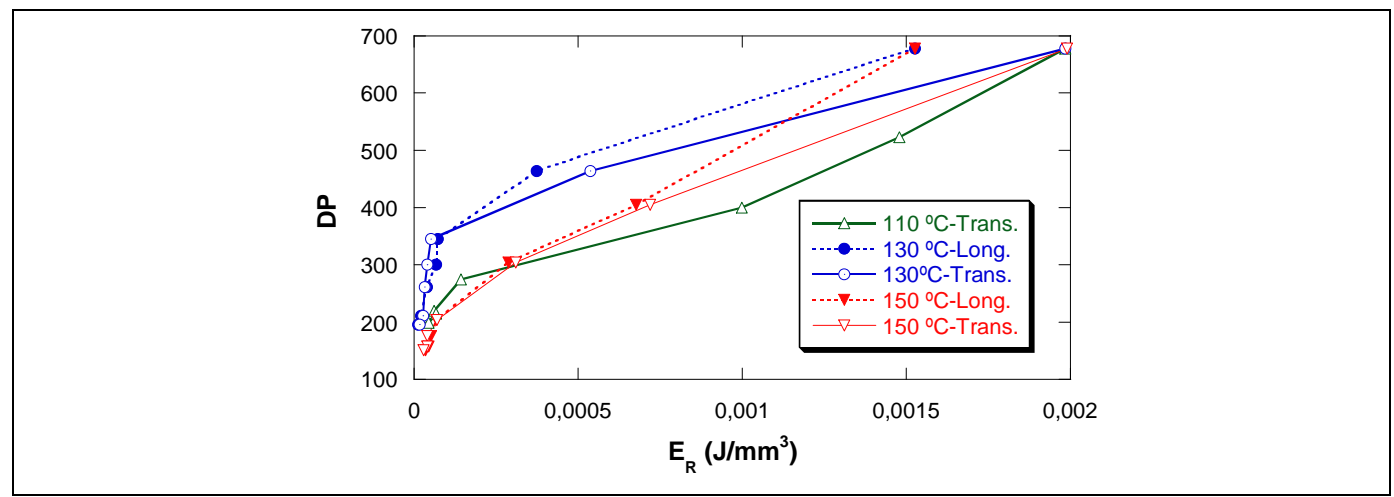

Fig. 11: DP vs test tensile parameters

\section{Fractographic analysis}

Fractography can be defined as the study of the fractured surfaces of materials. It is routinely used to determine the cause of failure through the study of the fractured surface characteristics. This technique can be used as a quick and simple procedure to determine the root cause of material failure (Greenhalgh and Hiley 2008). In some cases, fractography requires examination at a finer scale which is usually carried out using a Scanning Electron Microscope (SEM). This device has been used in this work to evaluate the rupture section of Kraft strips.

In the fractography of Fig. 12, it can be verified that the fibres in the rupture section have undergone significant strain when the Kraft paper is new. However, once the paper has been aged this strain is reduced, even at $72 \mathrm{~h}$ (Fig. 13). And after a considerable time of ageing, when DP is close to 200, the rupture is totally fragile (Fig. 14), with no strain in the fibres. This coincides with the macroscopic behaviour shown in the tensile tests. It has been verified that the failure mode has changed and this is critical, because when the behaviour of a material is fragile the crack initiation, propagation and final fracture occur instantly and the probability of partial discharges or short circuits would increase in the power transformer. Therefore, it is essential to define mathematical models which relate the macroscopic properties with the failure mode. 


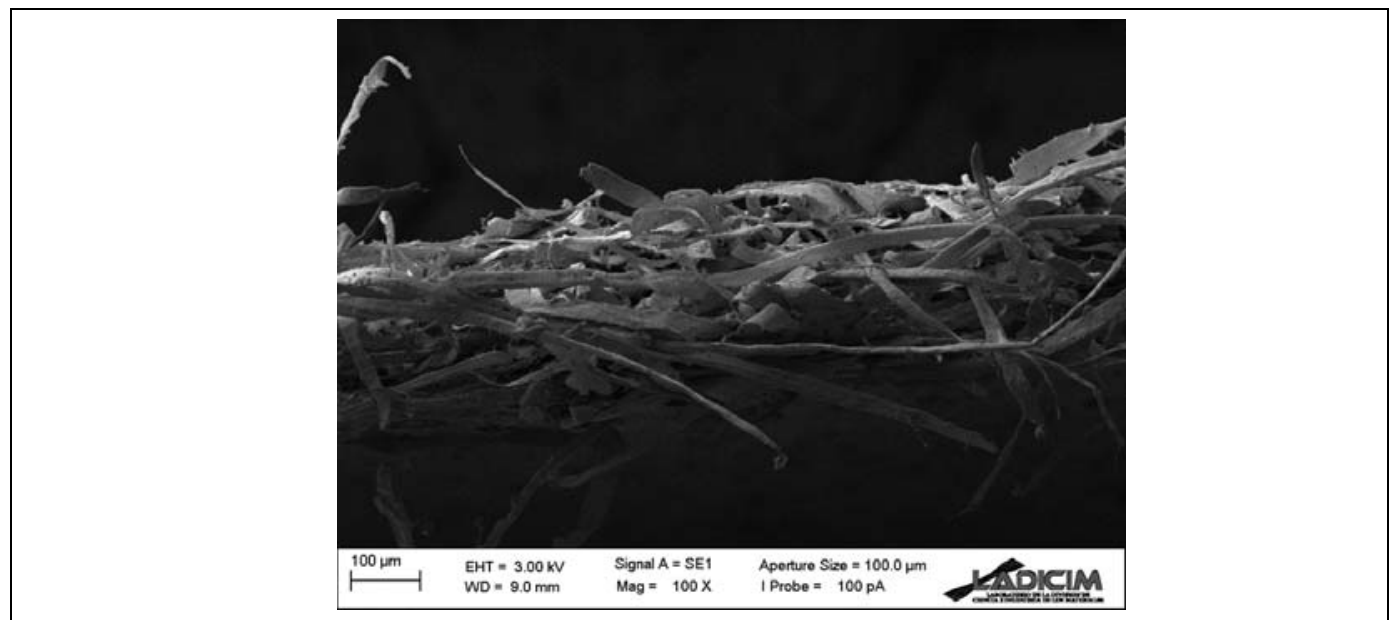

Fig. 12: Rupture section of the new Kraft paper

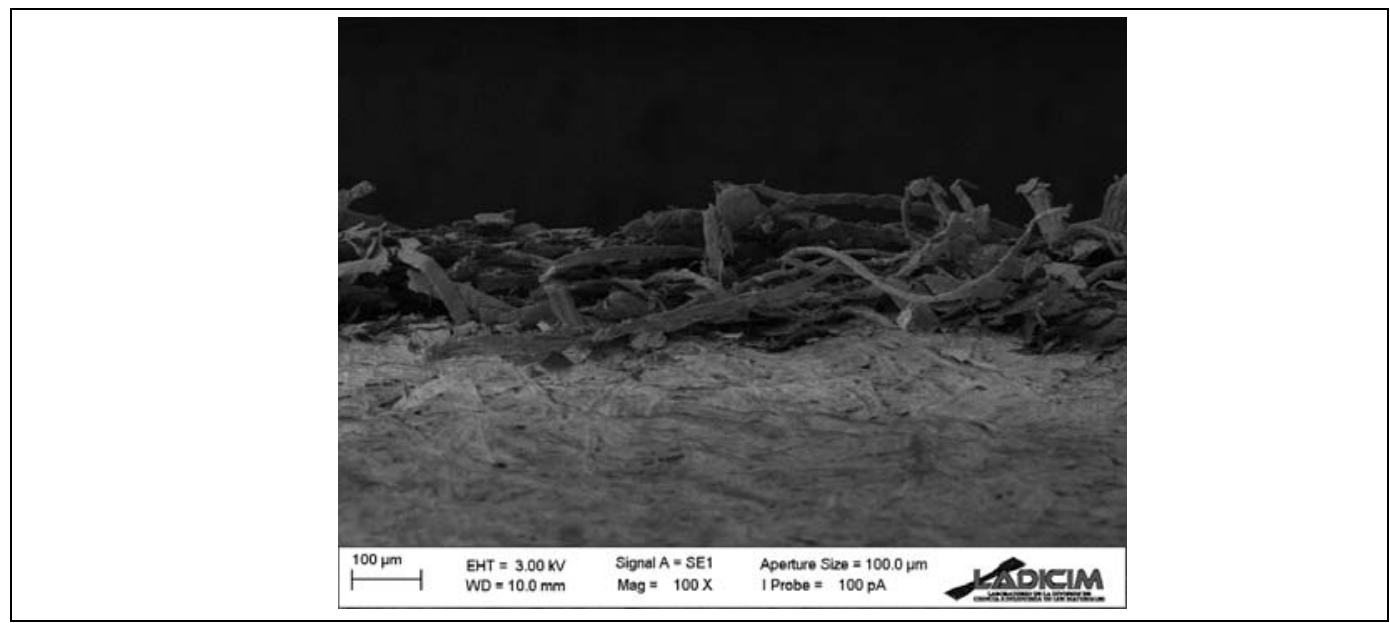

Fig. 13: Rupture section of Kraft after $72 \mathrm{~h}$ at $130^{\circ} \mathrm{C}$

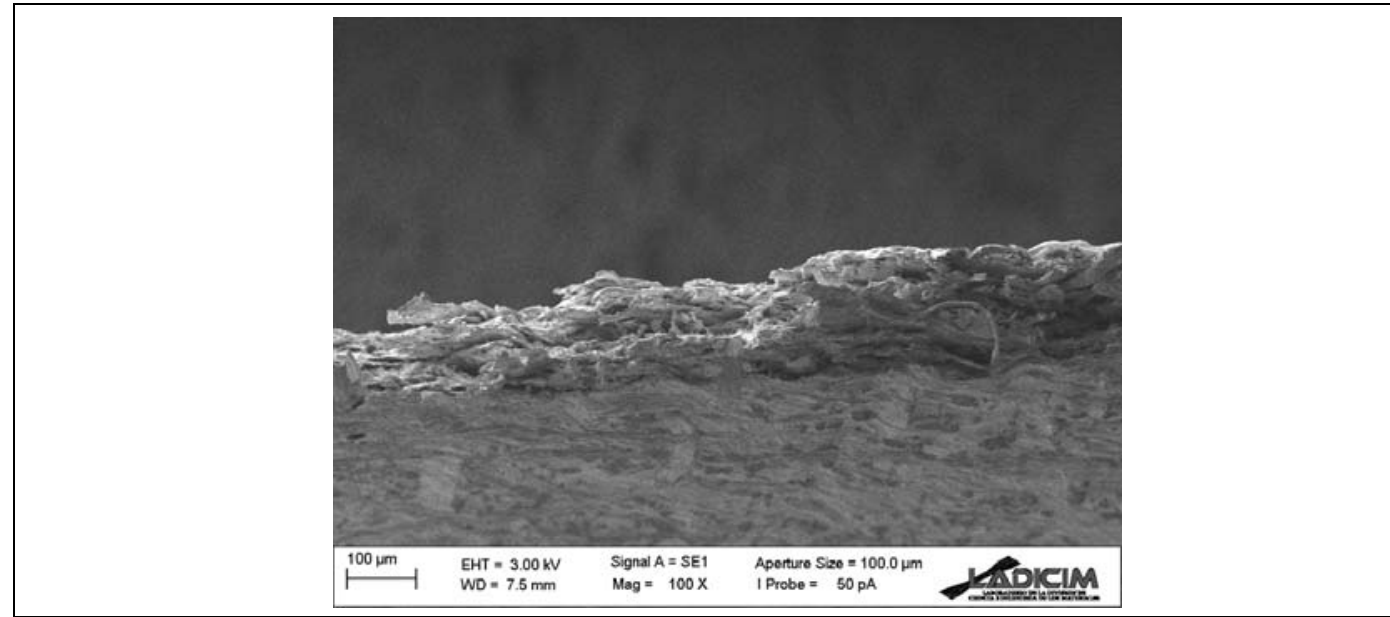

Fig. 14: Rupture section of Kraft after $168 \mathrm{~h}$ at $130^{\circ} \mathrm{C}$ 


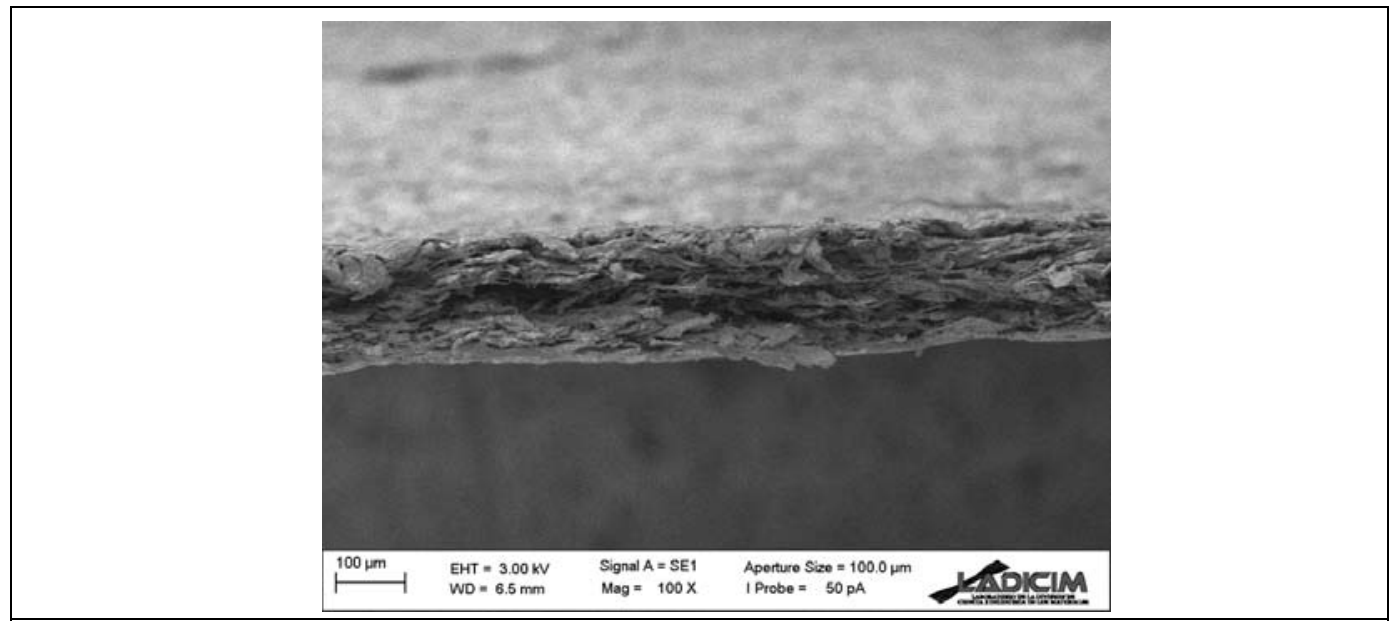

Fig. 15: Rupture section of Kraft after $260 \mathrm{~h}$ at $130^{\circ} \mathrm{C}$

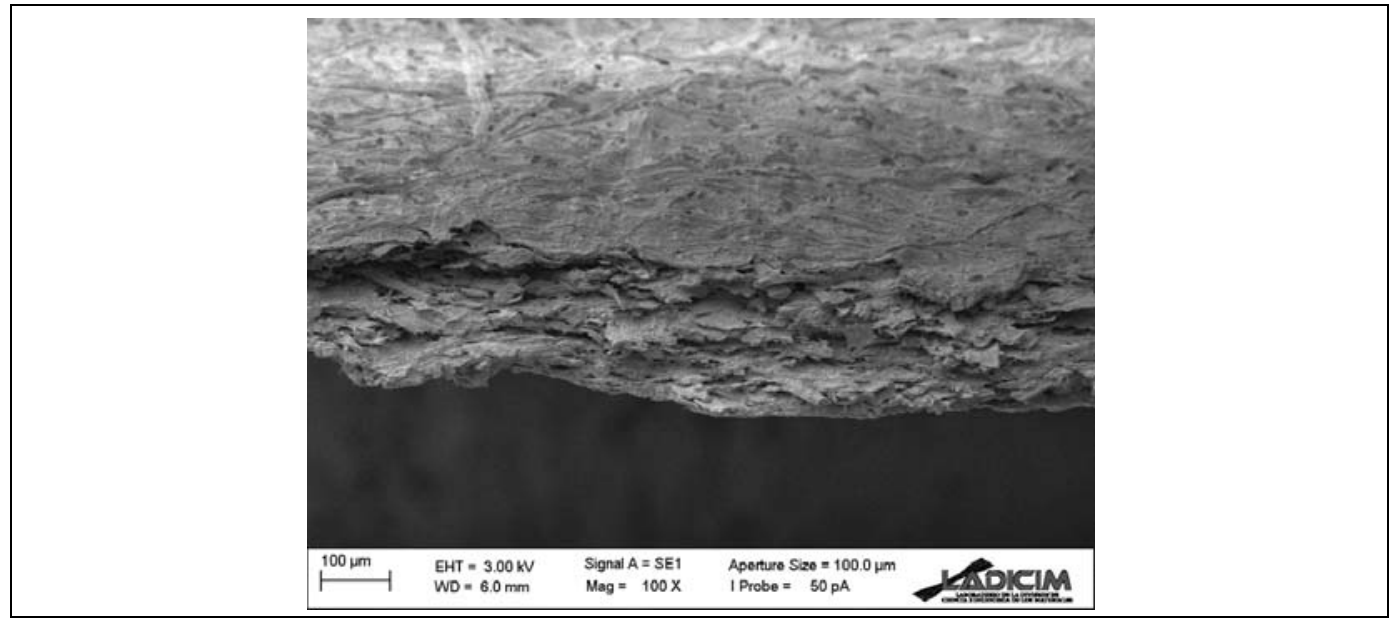

Fig. 16: Rupture section of Kraft after $425 \mathrm{~h}$ at $130^{\circ} \mathrm{C}$

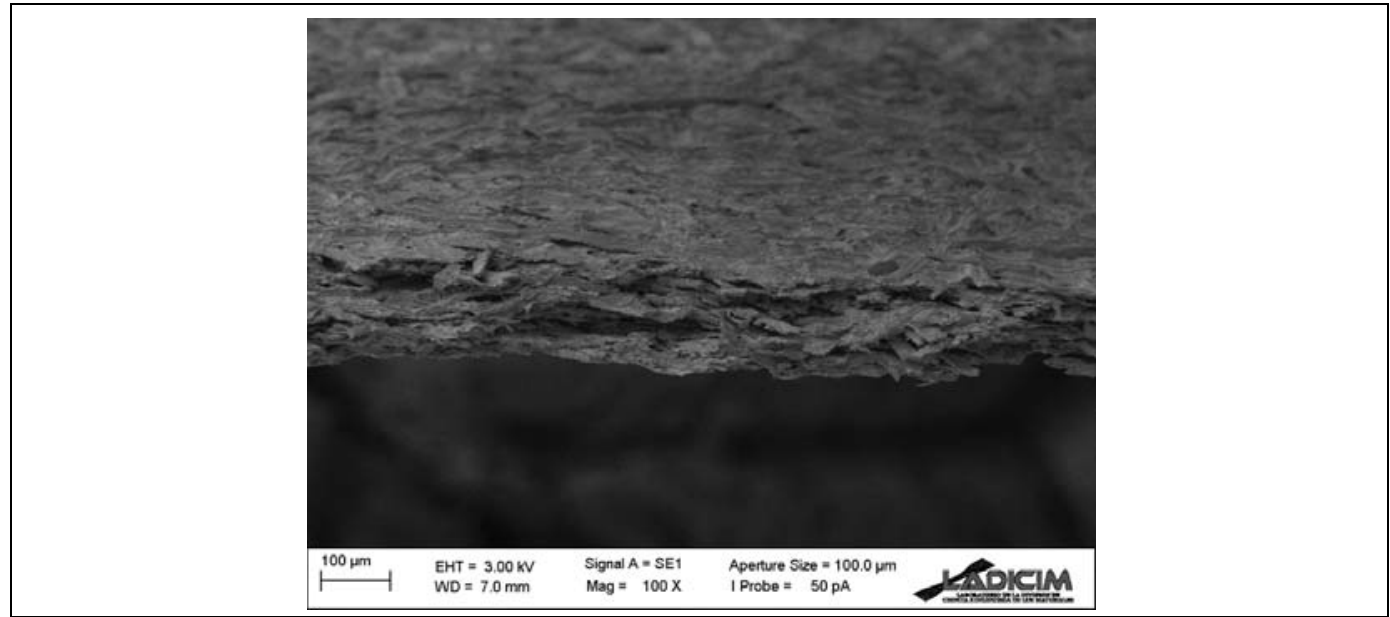

Fig. 17: Rupture section of Kraft after $735 \mathrm{~h}$ at $130^{\circ} \mathrm{C}$ 


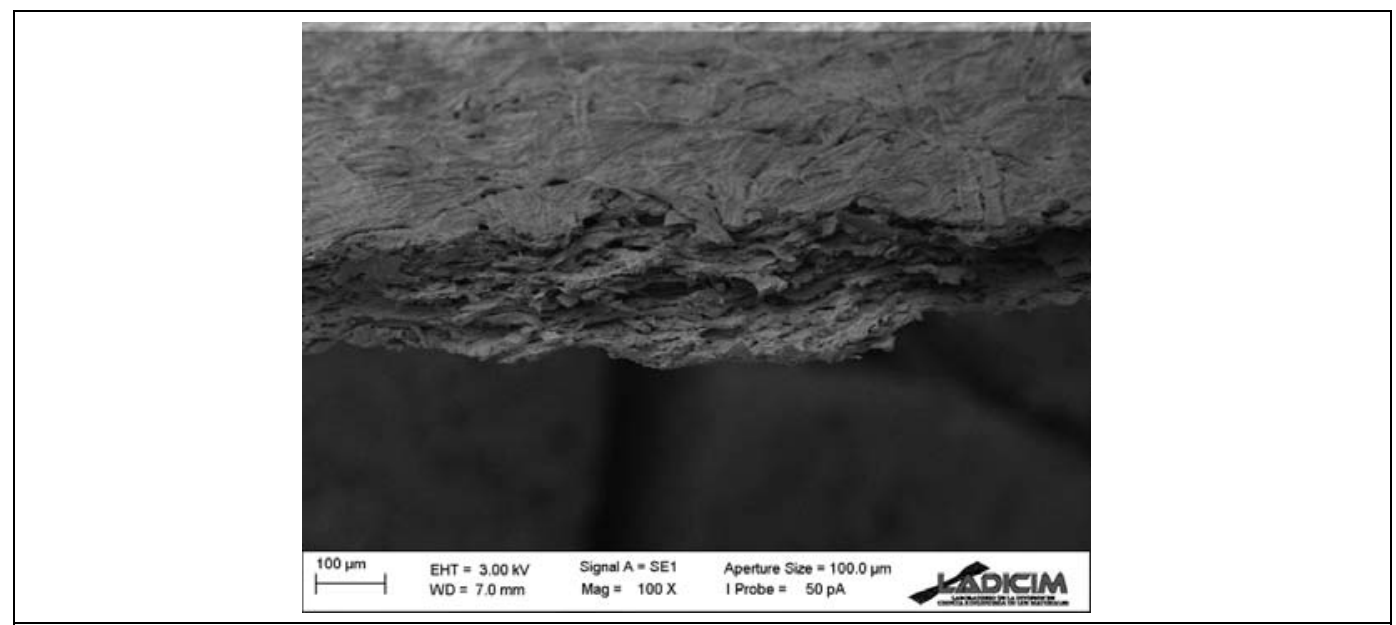

Fig. 18: Rupture section of Kraft after $1083 \mathrm{~h}$ at $130^{\circ} \mathrm{C}$

\section{CONCLUSIONS}

A behaviour model based on DP has been defined to predict the lifespan of Kraft paper used in the dielectric system of power transformers. This model is a function of the time and the temperature at which the paper is aged. Also, the loss of mechanical properties has been analyzed as the paper deterioration progresses, proving that the mechanical properties of the paper are already minimal before reaching the critical conditions established for the DP. Therefore, it might be advisable to revise the critical values of properties such as $\mathrm{DP}$ and $\sigma \mathrm{R}$ in order to establish when the end of life of dielectric paper has been achieved. Additionally, a fractography analysis should be carried out to include the results in new mathematical models that consider not only new critical values, but also values which mark the change of failure mode undergone by Kraft paper when this is used in power transformers as a dielectric solid. 


\section{REFERENCES}

Abelmalik AA, Fothergirl JC, Dodd SJ (2013) Ageing of Kraft paper insulation in natural ester dielectric fluid. In: IEEE International Conference on Solid Dielectrics (ICSD), Bologna, Italy, 541-544. doi: 10.1109/ICSD.2013.6619678

Carcedo J, Fernández I, Ortiz A, Delgado F, Renedo C, Arroyo A (2016) Quantitative study on the ageing of Kraft paper in vegetable oils. IEEE Electrical Insulation Magazine 32(6): 29-35. doi:

10.1109/MEI.2016.7656808

Ding HZ, Wang ZD (2008) On the degradation evolution equations of cellulose. Cellulose 15:205224. doi:10.1007/s10570-007-9166-4

Emsley AM, Stevens GC (1994) Review of chemical indicators of degradation of cellulosic electrical paper insulation in oil-filled power transformers. IEE Proceedings on Science, Measurement and Technology 141(5):324-334. doi: 10.1049/ip-smt:19949957

Fofana I (2013) 50 Years in the development of insulating liquids. IEEE Electrical Insulation Magazine 29(5): 13-25. doi: 10.1109/MEI.2013.6585853

Gasser HP, Huser J, Krause C, Dahinden V, Emsley AM (1999) Determining the ageing parameters of cellulosic insulation in a transformer. In: Eleventh international symposium on high voltage engineering, London, UK, 4.143-4.147. doi: 10.1049/cp:19990813

Greenhalgh ES, Hiley MJ (2008) Fractography of polymer composites: current status and future issues. In: Proceedings of the 13th European conference on composite materials (ECCM13), Stockholm, Sweden, 1-15.

Heywood RJ, Emsley AM, Ali M (2000) Degradation of cellulosic insulation in power transformers part I: factors affecting the measurement of the average viscometric degree of polymerisation of new and aged electrical papers. IEE Proceedings on Science, Measurement and Technology 147(2): 86-90. doi: 10.1049/ip-smt:20000076

Hill DJT, Le TT, Darveniza M, Saha T (1995) A study of degradation of cellulosic insulation materials in a power transformer, part 1. Molecular weight study of cellulose insulation paper. Polymer Degradation and Stability 48(1): 79-87. doi: 10.1016/0141-3910(95)00023-F Hill DJT, Le TT, Darveniza M, Saha T (1995) A study of degradation of cellulosic insulation materials in a power transformer part 2: tensile strength of cellulose insulation paper. Polymer Degradation and Stability 49(3): 429-435. doi: 10.1016/0141-3910(95)00100-Z

Hill DJT, Le TT, Darveniza M, Saha T (1996) A study of degradation of cellulosic insulation materials in a power transformer part 3: degradation products of cellulose insulation paper. Polymer Degradation and Stability 51(2): 211-218. doi: 10.1016/0141-3910(95)00204-9 Hoom J, Ki Park D, Ok Han S (2010) Estimation for degradation characteristics of cellulose paper used in oil-filled transformer and analysis for correlationship using statical treatment. In: Conference on precision electromagnetic measurements (CPEM), Daejeon, Korea (South), 13-18. doi: 10.1109/CPEM.2010.5544170 
Kalariya K, Kannad H, Vyas D, Gandhi P (2007) A review on ageing of power transformer and insulation life assessment. In: POWERENG International Conference Power Engineering, Energy and Electrical Drives. Setubal, Portugal, 12-14. doi: 10.1109/POWERENG.2007.4380104 Koch M, Tenbohlen S, Giselbrecht D, Homagk C, Leibfried T (2007) Onsite, online and post mortem insulation diagnostics at power transformers. Cigrè 23, Brugge, Belgium, 1-8.

Leibfried T, Jaya M, Majer N, Schäfer M, Stach M, Voss S (2013) Postmortem investigation of power transformers-profile of degree of polymerization and correlation with furan concentration in the oil. IEEE Transactions on Power Delivery 28(2): 886-893. doi:

10.1109/TPWRD.2013.2245152

Levchik S, Scheirs J, Camino G, Tumiatti W, Avidano M (1997) Depolymerization processes in the thermal degradation of cellulosic paper insulation in electrical Transformers, Polymer Degradation and Stability 61(3): 507-511. doi: 10.1016/S0141-3910(97)00249-8 Lundgaard L, Allan D, Höhlein IA, Clavreul R, Dahlund MO, Gasser HP, Heywood R, Krause C, Lessard MC, Saha TK, Sokolov V, Pablo A (2007) Ageing of cellulose in mineral-oil insulated transformers. Technical Brochure 323, D1.01.10.

Madavan R, Balaraman S (2016) Failure analysis of transformer liquid-solid insulation system under selective environmental conditions using Weibull statics method. Engineering Failure Analysis 65: 26-38. doi: 10.1016/j.engfailanal.2016.03.017

Martins MA, Fialho M, Martins J, Soares M, Castro MC, Campelo HMR (2011) Power transformer end-of-life assessment-Pracana case study. IEEE Electrical Insulation Magazine, 27(6): 15-26. doi: 10.1109/MEI.2011.6059980

Mirazie M, Gholami A, Tayebi HR (2009) Insulation condition assessment of power transformers using accelerated ageing tests. Turkish Journal of Electrical Engineering \& Computer Science 17(1): 39-54. doi:10.3906/elk-0802-5 Murugan R, Ramasamy R (2015) Failure analysis of power transformation for effective maintenance planning in electric utilities. Engineering Failure Analysis 55:182-192. doi: 10.1016/j.engfailanal.2015.06.002

Oommen TV, Prevost TA (2006) Cellulose insulation in oil-filled power transformers: part II maintaining insulation integrity and life. IEEE Electrical Insulation Magazine 22(2): 5-14. doi: 10.1109/MEI.2006.1618996

Perrier C, Coulibaly M, Marugan M (2016) Efficiency of ageing markers for different transformer insulation systems. In: IEEE International Conference on Dielectrics (ICD), Montpellier, France, 1-4. doi: 10.1109/ICD.2016.7547743

Prevost TA, Oommen TV (2006) Cellulose insulation in oil-filled power transformers: Part I history and development. IEEE Electrical Insulation Magazine 22(1): 28-35. doi:

10.1109/MEI.2006.1618969

Prevost TA, Gasser HP, Krause C (2007) The value of post-mortem investigations for the condition assessment of power transformers. Weidmann-ACTI Inc. Sixth Annual Technical Conference, St. Pettersburg, USA.

Rodriguez-Cellis EM, Duchesne S, Jalbert J, Ryadi M (2015) Understanding ethanol versus methanol formation from insulating paper in power transformers. Cellulose 22(5): 3225-3236. doi: 10.1007/s10570-015-0693-0 
Widyanugraha T, Rachmad R, Suwarno W (2015) DGA and tensile strength test on accelerated thermal ageing of ester oil and Kraft paper. In: International Conference on Electrical Engineering and Informatics (ICEEI), Bali, Indonesia, 177-180. doi: 10.1109/ICEEI.2015.7352491

Zhuravleva N, Reznik A, Tukacheva A, Kiesewtter D (2016) The study of thermal ageing components paper-impregnated insulation of power Transformers. In: Young Researchers in Electrical and Electronic Engineering Conference (EIConRusNW), St. Petersburg, Russia, 747751. doi: 10.1109/EIConRusNW.2016.7448288 